All attempts to elicit a history failed. The patient always foiled every question by his silence.

Under pentothal anaesthesia the stone was removed from a cavity (see Fig. 2), with smooth dense avascular walls, at far end of which was an opening into urethra, but this apparently was too small for repassage of the stone which measured about $\frac{1}{3}$ by $\frac{1}{4}$ inch. One assumes that the stone had reached its peri-urethral position by ulceration behind an anterior urethral stricture, and probably was aided in its passage by the formation of a peri-urethral abscess into which it passed, and from which the present sinuses burrowed through the glans to the surface. The sinuses now passed through a corpus spongiosum much fibrosed and almost avascular-clearly the end of a long-treasured process. In addition to treatment of the bacterial infection and dilatation of the stricture, the patient was given anti-syphilis treatment, with little or no effect except to turn him gonococcus free. After 10 months' dumb endurance of these efforts, which had made little change in the " sprinkler" "effect on micturition, he suddenly spoke up for amputation. Amputated.

V.D. Clinic,

Seamen's (Albert Dock) Hospital

H. M. HANSCHELL, D.S.C., M.R.C.S.

\title{
(1) TUBERCULOUS EPIDIDYMITIS ASSOCIATED WITH OR REACTIVATED BY ACUTE GONORRHOEA
}

The following case, which was seen in the clinic during the past year, seems to be of interest because of the apparent rarity of the condition.

\section{Case history}

A foreign seaman aged 23 years attended the clinic on 1st November 1943, complaining that he had had a discharge for fourteen days and a swelling of his left testicle for seven days.

On examination, he showed a purulent urethral discharge and marked urinary haze. Smears showed the presence of much pus and gonococci. There was an acute left-sided epididymitis and bilateral prostato-vesiculitis. The right testis and epididymis had been removed in boyhood; the possible significance of this operation was not realized at the time. The gonococcal complement fixation test was positive; the Wassermann reaction was negative.

Treatment with $\mathbf{2 0}$ grammes of sulphathiazole in four days, combined with gentle local irrigation, cleared the urinary haze and produced a temporary cessation of the urethral discharge (until 16th November, when pus and gonococci were again present in the smears) but effected no improvement in the condition of the epididymis, prostate and seminal vesicles. In accordance with the clinic routine a course of detoxicated gonococcal vaccine was given. This was followed by a further $\mathbf{4 0}$ grammes of sulphathiazole in eight days (2nd-10th December) but without success; the urethral discharge persisted with pus and gonococci still present; no clinical improvement was observed in the state of the epididymis, prostate and vesicles.

In view of the tendency to relapse, hyperpyrexial treatment was decided on ; three fever sessions, each of 8 hours at $106^{\circ}-106 \cdot 8^{\circ} \mathrm{F}$., were induced between 29 th December and 27 th January. There was slight clinical improvement after the first and second, followed by relapse ; after the third fever there was no further urethral discharge nor any further bacteriological evidence of gonorrhoea. The left epididymitis and bilateral prostatitis and vesiculitis persisted, although the real cause was unsuspected until, on 9th March, a cold abscess appeared at the lower pole of the left epididymis. This was at first regarded as a residual condition and it was aspirated. Smears of the aspirated material showed pus cells but no gonococci; a spread stained by the Ziehl-Neelsen method showed tubercle bacilli, a finding which was subsequently confirmed by the hospital bacteriologist. Tubercle bacilli were not found in the urine, but $x$-ray examination of the chest showed evidence of pulmonary tuberculosis. Multiple chronic sinuses developed in the scrotum and a tuberculous ulcer on the glans penis. Surgical intervention was advised but refused. The patient was then transferred to a sanatorium.

\section{Commentary}

I have been unable to find any record of a similar case in the literature, although, among the various predisposing causes of genito-urinary tuberculosis, gonorrhoea is frequently mentioned as being the chief. Thus, Hamilton Bailey writes that examples of gonorrhoeal infection followed by tuberculous epididymitis are few 
and far between, although cases are on record where both gonococci and tubercle bacilli have been isolated in excised specimens. Schuchardt is quoted by Watson Cheyne as having found tubercle bacilli present in some cases of gonorrhoea. Of four cases with quiescent testicular tuberculosis whom Keyes saw through attacks of gonorrhoea, two had testicular exacerbations and two did not. Lastly Campbell, in a review of 3,000 cases of gonococcal epididymitis, states that, whereas acute epididymitis due to other organisms may occur even in the presence of a gonococcal urethritis, such cases are most rare and open to question.

As a rule the presence of an acute epididymitis in association with a gonococcal urethritis is regarded as diagnostic of gonococcal epididymitis. The occurrence of a gonococcal epididymitis in an organ which is already the site of a latent tuberculosis is rare, and for this reason the possibility that reactivated tuberculosis is responsible for the continuance of the epididymitis may quite easily be overlooked. The alternative explanation, which from the onset and history seems less likely, is that tubercle bacilli from the pulmonary focus have attacked an epididymis already damaged by gonococcal infection. The unusually prolonged course of an acute gonococcal epididymitis and the formation of the cold abscess led to the consideration of tuberculosis as the probably correct diagnosis. In this case the history of a previous epididymectomy and orchidectomy was another clear indication that a latent tuberculosis might have been reactivated, thus causing the persistence of the epididymal lesion.

An analogous diagnostic problem was described by Salmond in a case of tuberculous salpingitis associated with an acute gonorrhoea.

C. P. HEYWOOD, M.B., Ch.B.

\section{REFERENCES}

Bailey, H. (1936) Diseases of the Testicle, London.

Bumpus, H. C., Jun., and Thompson, G. J. (1928) Surg. Gynec. Obstet., 47, 791.

Campbell, M. F. (1927) Ann. Surg., 86, 577.

Cheyne, W. W. (1899) Brit. med. J., 2, 1779.

Keyes, E. L., Jun. (1907) Ann. Surg., 45, 918.

Kretschmer, H. L. (1928) Surg. Gynec. Obstet., 47, 652.

Salmond, M. (1927) Lancet 1, 228.

\section{(2) LATE ONSET OF BUPHTHALMOS IN ASSOCIATION WITH CONGENITAL SYPHILIS}

Two cases which exhibited the association have been seen at this clinic during the past eighteen months.

\section{Case histories}

Case 1.-This female patient first attended the clinic in June 1943, at the age of 26 years. She had been undergoing irregular treatment at other clinics since 1934, when a diagnosis of congenital syphilis (interstitial keratitis, Hutchinson's teeth and positive Wassermann reaction) was established. Before she came under our observation and treatment she had had a total of 22.85 grammes of neoarsphenamine, 13.8 grammes of bismuth and 1 gramme of mercury. There had been a recurrence of the interstitial keratitis in 1939. The last Wassermann reaction, tested in 1941, had given a positive result.

On examination there was a subacute interstitial keratitis of the right eye; the left eye showed residual corneal opacities and the iris was slightly distorted. The Wassermann reaction result was doubtful. On clinical examination of the central nervous system no abnormality could be detected and the cerebro-spinal fluid was completely negative.

Treatment was resumed and in the next three months she was given 4.95 grammes of neoarsphenamine and 2.8 grammes of bismuth, after which she had a rest of one month. When she returned she had developed a buphthalmos of the right eye ; the Wassermann reaction was now negative. As it was considered possible that the buphthalmos might have been precipitated by over-zealous treatment, the patient was referred to the Eye Infirmary for the ophthalmologist's opinion; we were advised to continue treatment. Three more courses of neoarsphenamine and bismuth were given, during which there was a slow improvement in the sight of the right eye. The Wassermann reaction remained negative. 